\title{
A Perception-based Investigation on Corruption in Higher Education: Evidence from the Republic of Moldova
}

\author{
Victoria Butmalai (corresponding author) \\ College of Public Administration, Huazhong University of Science and Technology, \\ Address: 1037 LouYu Road, Huazhong University of Science and Technology, \\ Hongshan District, Wuhan, Hubei 430074, People's Republic of China \\ E-mail: victoriabutmalai@gmail.com
}

Liu Qijun,

College of Public Administration, Huazhong University of Science and Technology, Address: 1037 LouYu Road, Huazhong University of Science and Technology, Hongshan District, Wuhan, Hubei 430074, People's Republic of China E-mail: qijun-liu@163.com

Received: Feb. 4, 2021 Accepted: Mar. 1, 2021 Online published: Mar. 7, 2021 doi:10.5296/jpag.v11i1.18280～URL: https://doi.org/10.5296/jpag.v11i1.18280

\begin{abstract}
The study sheds light on the phenomenon of corruption in the Republic of Moldova's Higher Education System. It provides tangible evidence that corruption in the university environment isn't a merely unfounded rumor but a sad reality, sometimes challenging to capture and even more difficult to change. The research, exploratory in its nature, has thoroughly examined and analyzed the perceptions of the main education actors directly involved in the academic processes in order to discover the extent and the different facets of educational corruption and provide recommendations for preventing and opposing the phenomenon.

To empirically understand the roots and dimensions of corruption in Moldova's higher education, the adopted methodology was based on two approaches: qualitative and quantitative.
\end{abstract}




\section{MlMacrothink}

Journal of Public Administration and Governance

ISSN 2161-7104

2021, Vol. 11, No. 1

The qualitative part of the study, representing as well the preparatory basis for the quantitative approach, was conducted in two stages combining individual interviews and focus groups with the participation of the main educational stakeholders, namely: professors, students, and administrative officials. The quantitative phase included a broad survey based on three questionnaires executed on a sample of 671 respondents. The sample was composed of professors, students, and administrative personnel. The survey results show that for the three categories of actors directly involved in university life, corruption is a common phenomenon, seriously harming the image of the Moldovan universities and endangering the processes of human capital formation. The causes of corruption find their roots in the ineffective human and procedural management within the Higher Education system, Moldovan culture, and various educational actors' behaviors.

Keywords: corruption, perception of corruption, higher education (HE), higher education institutions (HEI), educational actors

\section{Introduction}

In all human societies, especially modern societies, education is one of the most powerful instruments for both man's development and transformation of human society. For many people worldwide, education represents the vector of hope for a better future (Milovanovitch, 2014). It plays the role of a social elevator allowing the most disadvantaged to access a higher social rank through diplomas promising professional integration and subsequent ascension. However, this equation remains theoretical and becomes more and more insoluble in practice when rampant corruption destabilizes education institutions' structured and regulated functioning. One of the prerogatives of education in the public sector is to provide all citizens equal opportunities to access education, regardless of income or social status. By spreading in this highly sensitive sector, corruption risks hampering a country's economic growth (Osipian, 2009). One of the missions of national education is to issue diplomas that meet quality academic and professional standards and the expectations of the job market. This exchange of good practices between the "suppliers" of skills and the recruiters is thus based on credibility and trust in the education system. Corruption disrupts this relationship and shatters this pact by helping to train unqualified graduates who would consequently obtain positions of responsibility in the labor market. Therefore, "meritocracy" risks turning into "mediocracy."

In addition, the corrupt system provides graduates with little inclination towards integrity, given the trivialization and acceptance of unethical behavior. Such a situation could constitute a fertile ground for the development of corruption at all political and administrative levels and even within schools. The education sector is particularly vulnerable (Milovanovitch, 2014) and susceptible to political manipulation due to its economic importance and its weight in terms of human resources. Corruption in education not only inhibits the building of a prosperous modern society (Heyneman, 2002) but also can have a devastating impact on a country's well-being. Perhaps the most severe cost of corruption in education is the loss of trust. If students come to believe that school or university admission and marks can be bought, a country's political and economic future is in great danger. Breaking the silence over 
corruption in higher education is a mammoth ongoing task, requiring combined efforts to ensure that educational objectives are achieved and that everyone receives the best possible study and career opportunities.

Obviously, the fight against corruption in the specific field of higher education must be considered a top priority. All aspects related to this fight require careful consideration and a multi-perspective approach as corruption does not impact only the volume, the quality, and the efficiency of educational services, but also equity in education and public confidence in education systems.

\section{An Education-Specific Understanding of Corruption}

Plato, Aristotle, Thucydides, and Machiavelli used the term "corruption" above all to qualify the moral health of a society. From ancient Greece to the philosophers of the eighteenth century, the expression qualified a degeneration of institutions, more precisely a distortion of the principles that constitute the foundation of the political system (Johnston, 1996). For Montesquieu (2002), in particular, all governments are subject to corruption. For the great thinker, "the corruption of each government almost always begins with the corruption of moral principles."

Therefore, it seems that the problem of corruption is as old as the Government itself (Campbell, 2013), and no country is likely to have immunity towards corruption (Everhart et al., 2003; Shleifer \& Vishny,1993). While, by definition, it may have a range of cultural and legal understandings (Melgar et al. 2010), the phenomenon is recognized as a major impediment to economic development in many areas of the world (Blackburn et al. 2010).

A review of the literature of the main works that have studied the phenomenon of corruption indicates that this concept has been defined in different ways. Among various definitions, some seemed relevant to us, such as those of Bardhan (1997) or Tanzi (1998), who qualified this phenomenon as a form of abuse of public power for private benefit. Moreover, the most common definition has been put forward by the World Bank, which states that corruption is "the abuse of public office in order to obtain a private advantage." Palmier's definition (1983) is similar to that of the World Bank in considering it as "the use of a public office for the benefit of private interests."

In this regard, it should be summarized that corruption, in general, is an abuse of power for the achievement of personal ends and material profits (Frimpong and Jacques, 1999). In the field of education, corruption was defined by the UNESCO International Institute for Educational Planning as "the systematic use of a public charge for a private advantage, which has a significant impact on the availability and quality of educational goods and services and, consequently, on access, quality or equity of education" (Hallak and Poisson, 2009). From this definition, three elements can be identified:

- corruption in the education system is based on the traditional definition of corruption in the public sector; 
- it limits the scope of the behaviors examined to those which result from the dysfunction of the system and excludes individual behaviors observed episodically;

- it establishes a link between these behaviors and their effect on the system (the reduction of resources, the decline in their quality, or unequal distribution).

Heyneman (2007) highlights that the study of corruption in the education sector implies the recognition of a severe and socially significant consequence: corruption involves young people and teaches them immoral behaviors and the acceptance of corrupt practices. Chapman (2002) and Rumyantseva (2005) also underline that corruption in academia leads youth to accept corruption and makes them prone to involve in illegal activities. Chapman (2002) further believes that systemic and widespread corruption in the education sector "instills values which are highly destructive to the economic and social development of a country."

\section{Measuring Corruption}

The effective measurement of corruption has been a subject of great interest among scholars and professionals. Even though assessing corruption in an accurate and precise manner is inherently impractical, measuring corruption is still necessary and nonetheless conceivable (UNDP, 2008). In this sense, three main approaches were identified (Kaufmann D. et al., 2007): (i) assessing corruption through informed views of relevant stakeholders, by conducting surveys of government officials, business representatives, and individuals; (ii) by investigating the profiles of national bodies for identifying opportunities for corruption, mostly related to procurement processes, administrative and financial operations; and (iii) by inspecting targeted activities such as financial audits and budget spending transparency.

Most of the indicators used for measuring corruption are subjective and generally known as 'perceptions of corruption' (Campbell, 2013; Olken \& Pande, 2012). The use of purely objective measurements for assessing the phenomenon of corruption is rare, mainly due to the scarcity of objective resources. In many cases, even what researchers consider as an 'objective' measurement still relies, more often, on a perception-based indicator (Campbell, 2013; Urra, 2007). Following this idea, while objective indicators generally measure corruption through evidence-based quantitative data, the most accessible and frequently used method are still the opinion polls on corruption (Campbell, 2013). The extensive use of perception for measuring corruption can generate misleading conclusions. Objective evidence on corruption, however, is exceptionally scarce.

\section{Study Context: Moldovan Higher Education}

The current concern for corruption in Moldovan Higher Education is determined by the massive corruption level in the Moldovan Government itself. Moldova is one of the countries facing a worrying level of corruption. $96 \%$ of Moldovans surveyed declared corruption a major problem and identified it as the main cause of poverty (IRI Poll 2019).

According to the 2020 Corruption Perceptions Index, Moldova ranks 115nd out of 180 countries in corruption, demonstrating, since 2012, steadily increasing rates of perceived 
corruption. A high level of perceived corruption is destructive both at the individual and social level by cultivating a 'culture of distrust' towards related institutions (Melgar et al. 2010) and generating a cultural tradition that increases corruption's pervasiveness (Cabelkova \& Hanousek 2004). Similarly, the World Bank's Worldwide Governance Indicators (2018) report a decline of the country in all governance areas, especially in crucial areas such as the rule of law and corruption control. On average, Moldovans offer a bribe at least five times per year, with a value of informal payments varying between 50 and 20 thousand lei ( $\approx 2.5$ and 1000 Euros), as shown in a sociological study conducted in 2018 (IPP, 2018). Transparency International Moldova indicates as the most corrupt social services education, health, and police (Global Corruption Barometer, 2016). Education is declared as the sphere where informal payments have acquired the country's most expansive scale. Such a reputation certainly undermines the prestige of the education system as such. Lilia Carasciuc, the Executive Director of this non-governmental organization, affirms, "Corruption at Moldovan educational institutions is not simply illicit and ugly in its essence. It leads to the degradation of the country's ethical and moral fundamentals, the deterioration of education quality, and, accordingly, to the degradation of the labor force competitiveness. If the State fails to undertake resolute measures in this sphere, Moldova may well lose its economic competitiveness on the international market".

Moldovan universities are not ivory towers, nor are they isolated from societal norms. As an essential element of Moldovan social and economic life, corruption significantly affects academia. However, detecting a general climate steeped in corruption is not enough. It must be supplemented by studies that help to understand the phenomenon better, to see its manifestations, its causes, and the effects it is likely to have on the University and society in general. In practice, empirical evidence on corruption in the Republic of Moldova's Higher Education sector is scarce, apart from a few isolated corruption cases that reached the spotlight. Educational corruption is not frequently covered by the media because it is not seen as "hot news." Besides, it is often considered less important than other forms of corruption affecting society's normal functioning.

It is clear that corruption is systemic and well-organized in highly corrupt settings (Altbach, 2004; Chapman, 2002; Waite \& Allen, 2003). Consequently, Moldova's education sector is a rich field of opportunities for corruption, which hinders its smooth functioning and jeopardizes the achievement of all the objectives given to education. However, the few works published on this subject do not seem to offer a conclusive picture of the level of corruption existing in Moldovan higher education institutions (HEI) and the factors facilitating this phenomenon's flourishing in the Moldovan education sector.

Although there have not been many corruption cases in the educational system in the last years, this does not implicitly imply a low level of corruption in this area. Rather, it indicates that society tacitly accepts corruption cases in education. Thus, Moldova provides an opportunity to research an education system where claims of higher education's EUnionization representing mobility, effectiveness, and transparency coexist with claims of corrupt behaviors, limited mobility, and weak HEI. 


\section{Methodology}

To briefly review the broader methodological landscape, Creswell (2009) notes that social scientists can conduct three types of research: quantitative, qualitative, and mixed methods research. While the quantitative approach's advantage rests in its ability to segregate meaningful and generalizable patterns in large samples (the what), quantitative research lacks explanatory power as to the particularities of local cultures and complex contexts (the why and how). Over the years, both methodological approaches have gained validity and today remain invaluable in helping researchers understand various social science phenomena.

This study chose to rely on the additive value of mixed methodologies by combining multiple methods to reveal additional information. To best investigate the phenomenon of corruption in the country's higher education sector, we use exploratory sequential mixed methods. In this way, the first phase is a qualitative one and concludes with analysis producing more conceptual themes. The analysis results are used to direct the next quantitative phase. This approach's rationale lies in first exploring a topic before deciding what variables need to be measured.

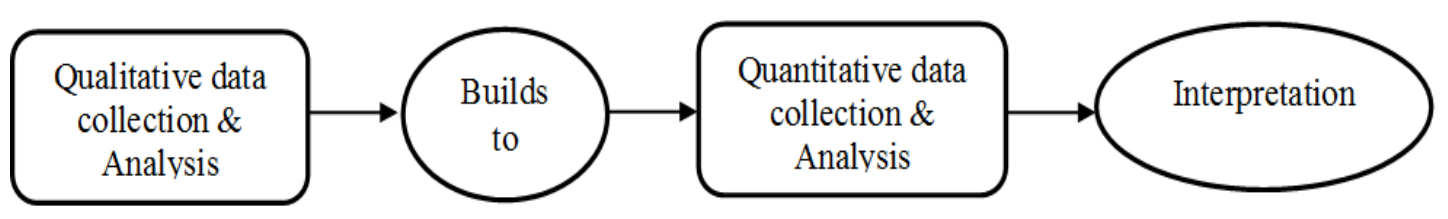

Figure 1. Exploratory sequential mixed methods research design

Source: (Creswell, 2012)

Semi-structured interviews were the primary data collection tool used in the qualitative part of the work. From the review of specialized literature, interview guides have been elaborated with a focus on corruption in education, in general, and in higher education, in particular. Collective interviews (focus groups) were conducted with groups of students and teachers. For administrators, it is the method of individual interviews that has been favored given the difficulties of bringing together administrators (heads of departments, deans, ministry officials) at the same time.

For the quantitative part, the current study has applied a semi-structured questionnaire comprising a mixture of scaled and open questions. Scaled questions (Likert scale) were used for gathering information from the respondents. For the purpose of our study, we constructed questionnaires targeting each category of educational actors. These questionnaires followed the descriptive nature of the research and allowed appropriate analyzes to be performed. The questionnaires were drafted to comply with drafting standards both in substance and in form. Also, the funnel principle has been respected in the presentation of the themes. In fact, the three versions of the questionnaire begin with a general question concerning the perception of the very existence of corruption in academia, to progress gradually towards details on the perception of forms, actors, frequency, reasons, denunciation, and refusal, anti-corruption actions, to finish with personal testimonies on cases of corruption. 


\subsection{Selected Sample}

Three types of actors constitute the main stakeholders at the Moldovan university level. These key players are the students, the academics (teacher-researchers), and finally, the administrators (elected and appointed leaders of the various organizations structuring the university system). The perception of these educational stakeholders is essential for assessing the existing dimensions and forms of corruption, their frequency, severity, and the means to reduce if not eradicate them. Therefore, regarding our sample, it was decided to use quota sampling for the students' category. This method, which consists of reproducing the mother population's characteristics on the sample, is one of the most reliable non-probabilistic methods, which allow the best representativeness.

For the teachers and the administrative staff, the questionnaire was administered using convenience and simple random sampling. Sample's representativeness was ensured by control criteria consistent with the study's objective. Thus, for the students' category, the gender and study cycle criteria were used to calculate the quotas. These criteria' choice is justified by a difference in the perceptions observed during the interviews in the qualitative study. For qualitative data, both purposive and random sampling techniques were employed to obtain information for the research (Creswell, 2012; Neuman, 2014).

\subsection{Data Collection}

The survey was carried out between January and April 2020 and resulted in three final sub-samples, the data being collected from a population of 671 respondents (550 students, 86 teachers, and 33 administrators - Table 1,2). The calculation of quotas based on population statistics for the 2019-2020 academic year (Source: Moldovan National Bureau of Statistics, 2019) is summarized in the table below. Table 1 shows that the composition of the final sample of students generally respected the quotas of the mother population. In administering the questionnaires, the purpose was to reach a larger number of universities and study cycles.

Table 1. Characteristics of the "Students" sub-sample

\begin{tabular}{|c|c|c|c|c|c|}
\hline \multicolumn{6}{|c|}{ Quota sampling for students } \\
\hline \multirow{3}{*}{$\begin{array}{l}\text { Total students population } \\
\text { in Moldova (in } \\
\text { 2019/2020) }\end{array}$} & \multicolumn{2}{|c|}{56800} & \multirow[t]{3}{*}{ Sample size } & \multicolumn{2}{|c|}{550} \\
\hline & $\mathrm{F}$ & $\mathrm{M}$ & & $\mathrm{F}$ & $\mathrm{M}$ \\
\hline & $59 \%$ & $41 \%$ & & $325(59 \%)$ & $225(41 \%)$ \\
\hline \multicolumn{3}{|c|}{ Distribution by study cycles and by gender } & \multicolumn{3}{|c|}{$\begin{array}{l}\text { Distribution by study cycles and by gender } \\
\text { within the sample }\end{array}$} \\
\hline \multirow[t]{3}{*}{ Bachelor (\%) } & \multicolumn{2}{|c|}{$73,5 \%$} & \multirow[t]{3}{*}{ Bachelor } & \multicolumn{2}{|c|}{404} \\
\hline & $\mathrm{F}$ & $\mathrm{M}$ & & $\mathrm{F}$ & $\mathrm{M}$ \\
\hline & $56,7 \%$ & $43,3 \%$ & & 294 & 110 \\
\hline \multirow{3}{*}{$\begin{array}{c}\text { Master and Integrated } \\
\text { studies }(\%)\end{array}$} & \multicolumn{2}{|c|}{$23,7 \%$} & \multirow{3}{*}{$\begin{array}{c}\text { Master and } \\
\text { integrated } \\
\text { studies }\end{array}$} & \multicolumn{2}{|c|}{130} \\
\hline & $\mathrm{F}$ & $\mathrm{M}$ & & $\mathrm{F}$ & $\mathrm{M}$ \\
\hline & $61,4 \%$ & $38,6 \%$ & & 79 & 21 \\
\hline \multirow[t]{3}{*}{$P h D(\%)$} & \multicolumn{2}{|c|}{2,8} & $P h D$ & \multicolumn{2}{|c|}{15} \\
\hline & $\mathrm{F}$ & $\mathrm{M}$ & & $\mathrm{F}$ & $\mathrm{M}$ \\
\hline & $52 \%$ & $48 \%$ & & 8 & 7 \\
\hline
\end{tabular}


Table 2. Characteristics of the "Teachers" and "Administrative personnel"sub-samples

\begin{tabular}{|l|l|l|c|}
\hline \multicolumn{2}{|c|}{ 86 University teachers } & \multicolumn{2}{c|}{ 33 Administrative staff } \\
\hline Men & 32 & Men & 12 \\
\hline Women Position & 54 & Women & 21 \\
\hline \multicolumn{2}{|c|}{} & \multicolumn{2}{c|}{ Position } \\
\hline Professor & 13 & Rectors & 3 \\
\hline Associate professor & 24 & Deans & 7 \\
\hline University lecturer & 31 & Deputy deans & 12 \\
\hline University assistant & 18 & Department Heads & 11 \\
\hline
\end{tabular}

According to Mitchell (1989), the survey response rate should be calculated as the number of returned questionnaires divided by the total sample sent initially to the survey. As indicated in the table below, a response rate of $95,8 \%$ supports the collected data's reliability.

Table 3. Total number of responses

\begin{tabular}{lccc}
\hline \multicolumn{1}{c}{ Category } & $\begin{array}{c}\text { Sample } \\
\text { size }\end{array}$ & $\begin{array}{c}\text { Actual no. of } \\
\text { respondents }\end{array}$ & Response Rate \\
\hline Students & 550 & 550 & $100 \%$ \\
\hline Teachers & 100 & 86 & $86 \%$ \\
\hline Administrative officials & 45 & 33 & $73.3 \%$ \\
\hline $\begin{array}{l}\text { Officials of the Ministry } \\
\text { of Education }\end{array}$ & 5 & 2 & $40 \%$ \\
\hline Total & $\mathbf{7 0 0}$ & $\mathbf{6 7 1}$ & $\mathbf{9 5 . 8 \%}$ \\
\hline
\end{tabular}

\subsection{Results Analysis}

The analysis of responses to the three different versions of the questionnaire was carried out using SPSS 24.0 software. The analyzes carried out are of two types:

- Descriptive analysis through the examination of response frequencies;

- Analyzes of the psychometric qualities of the scales of measurement of perceptions created through reliability and dimensionality.

Purification of measurement scales. Being the first of its kind in the Moldovan university sector, the quantitative part of the research required the development of measurement scales for the various concepts mentioned during the qualitative study conducted beforehand. These measurement scales were built around a set of items taken from participants' comments in the two focus groups and the semi-structured interviews. However, given the exploratory nature of this study, these newly created scales' psychometric qualities must be verified to ensure a minimum methodological rigor threshold in the data analysis. For this, the academic canons were followed by adopting a two-step approach:

- Testing the dimensionality of scales through the PCA technique (principal component analysis) after extracting the factors making up the scale;

- Testing the reliability of the scales through the calculation of Cronbach's alpha. 


\section{Mll Macrothink}

Journal of Public Administration and Governance

ISSN 2161-7104

2021, Vol. 11, No. 1

These two methods made it possible, via specific indicators, to ensure that the items retained by extracted factors measure the same thing and present satisfactory reliability and internal consistency (with a Cronbach Alpha > .70, an explained variance $>60 \%$, and KMO values greater than 0.60). The scales were thus refined for two categories of respondents: students and teachers, the administrative sample being relatively small.

Thus, the scales for which the psychometric indicators are satisfactory are the following:

1. Perception of the existence of corruption in HEI;

2. Perception of corruption in the different components of the university system;

3. Perceived forms of corruption;

4. Perception of factors favoring corruption at the University;

5. Perceived responsibility of the actors in the phenomenon of corruption at the University;

6. Perception of the consequences of corruption in HE;

7. Perception of anti-corruption actions.

\section{Findings and Discussion}

The exploratory qualitative and quantitative study carried out in Moldovan Higher Education made it possible to identify some main trends likely to shed light on the phenomenon of corruption in Moldovan academia, as a poorly studied subject and around which various assumptions have been made.

\subsection{Corruption in Moldovan Higher Education is not a Rumor}

The absence of any real "academic" study on corruption at the Moldovan University has either cast doubt on its real tangible existence or given rise to the most bizarre rumors about this phenomenon. Although based on the perceptions of three categories of university actors, the present exploratory study has the merit of lifting the veil on this phenomenon and drawing its outlines while awaiting more representative and more detailed research. This work thus breaks with the idea that corruption in Moldovan academia is mostly an unfounded rumor.

For a large majority of respondents $(78.2 \%$ of students, $88.1 \%$ of teachers, and $79.6 \%$ of administrators), corruption at the University is not a rumor (Table 4), and $69 \%$ of students, $64 \%$ of teachers, and $51.6 \%$ of administrators confirm its current existence.

Table 4. Perceptions of corruption pre and post Association Agreement European Union Republic of Moldova (AA EU - RM)

\begin{tabular}{|c|c|c|c|c|c|}
\hline Corruption & $\begin{array}{c}\text { currently } \\
\text { exists }\end{array}$ & $\begin{array}{c}\text { existed } \\
\text { before AA } \\
\text { EU - RM }\end{array}$ & $\begin{array}{c}\text { amplified } \\
\text { after AA } \\
\text { EU - RM }\end{array}$ & $\begin{array}{c}\text { a common } \\
\text { phenomenon }\end{array}$ & a rumor \\
& & & \\
\hline Administrative staff
\end{tabular}




\begin{tabular}{|l|l|l|l|l|l|}
\hline Disagree & $21.3 \%$ & $15.1 \%$ & $27.1 \%$ & $23 \%$ & $79.6 \%$ \\
\hline Somewhat agree & $27.1 \%$ & $22,3 \%$ & $29.2 \%$ & $25,3 \%$ & $11 \%$ \\
\hline Agree & $51.6 \%$ & $62.6 \%$ & $43.7 \%$ & $51.7 \%$ & $9.3 \%$ \\
\hline Teachers & $8.9 \%$ & $8.1 \%$ & $15.6 \%$ & $16.8 \%$ & $88.1 \%$ \\
\hline Disagree & $27,1 \%$ & $13.2 \%$ & $27.8 \%$ & $28.3 \%$ & $6.2 \%$ \\
\hline Somewhat agree & $64 \%$ & $78.7 \%$ & $56.7 \%$ & $54.8 \%$ & $5.6 \%$ \\
\hline Agree & $7.1 \%$ & $8.5 \%$ & $18.9 \%$ & $12.9 \%$ & $78.2 \%$ \\
\hline Students & $23,9 \%$ & $12.8 \%$ & $22.8 \%$ & $23.4 \%$ & $11.8 \%$ \\
\hline Disagree & $69 \%$ & $78.7 \%$ & $58.2 \%$ & $63.7 \%$ & $10 \%$ \\
\hline Somewhat agree & \multicolumn{5}{|l|}{} \\
\hline Agree &
\end{tabular}

For most respondents, it existed before 2014 (when the Association Agreement between the European Union and the Republic of Moldova was signed), still exists and is a common phenomenon. For teachers and students, it has even grown since 2014. Two factors could explain this result. On the one hand, the Association Agreement's signing has imposed the Moldovan Government to implement multiple structural and legal reforms to take a firm stand against corruption by enhancing transparency and people's awareness. The reform process was accompanied by an increase in the freedom of expression, said to have, among other things, disrupted the Moldovan university system. Thus, "tongues have loosened," and the leaden cover that has long weighed on students, teachers, and administrators would begin to break down gradually. On the other hand, it is possible that the multiplication of media sources and the preponderance of information flows via social networks (an essential vector of information for students and teachers) would have fueled the perceptions of respondents related to the existence and the intensity of corruption in academia.

\subsection{University Corruption: A Cultural and Structural Issue}

An anchored cultural dimension. It emerges from the respondents' perceptions that the phenomenon of corruption in Moldovan Higher Education is mainly based on a strong cultural component since the overwhelming majority of students $(75.1 \%)$, teachers $(81.2 \%)$, and administrators $(68.3 \%)$ consider the lack of values and principles one of the major factors favoring corruption. The cultural aspect is also highlighted by most of the three categories of respondents and concerns the lack of a culture of denunciation. This observation is again a cultural characteristic of Moldovan society, which is reluctant to denounce it. This cultural specificity is all the more accentuated as denunciation within the university system's framework can have severe consequences for the three actors, whether they are students, teachers, or administrators.

Students may be reluctant to denounce acts of corruption, fearing reprisals and possible obstacles that might compromise their academic and professional future. For their part, teachers and administrators would be reluctant to denounce corruption, fearing that this might endanger their professional and career development or simply act out of solidarity with their peers. The structural factor is also raised by $69.1 \%$ of students via the flaws of the university 
system.

Table 5. Factors perceived by students as favoring corruption

\begin{tabular}{|l|c|c|c|}
\hline \multicolumn{1}{|c|}{ Factors of corruption } & Disagree & $\begin{array}{c}\text { Moderately } \\
\text { agree }\end{array}$ & Agree \\
\hline Low remuneration of teachers & $54.8 \%$ & $23.9 \%$ & $21.4 \%$ \\
\hline The low remuneration of administrative staff & $42.9 \%$ & $26.6 \%$ & $30.5 \%$ \\
\hline Lack of a culture of denunciation & $9.5 \%$ & $20.7 \%$ & $69.8 \%$ \\
\hline The flaws in the university system & $11.8 \%$ & $19.1 \%$ & $69.1 \%$ \\
\hline The trivialization of the phenomenon of corruption & $12.6 \%$ & $23.4 \%$ & $63.9 \%$ \\
\hline $\begin{array}{l}\text { Lack of values and principles among the different } \\
\text { actors }\end{array}$ & $6.8 \%$ & $18.1 \%$ & $75.1 \%$ \\
\hline The incompetence of certain officials and/or teachers & $10.8 \%$ & $21.1 \%$ & $68.1 \%$ \\
\hline Lack of a control system & $12.1 \%$ & $19 \%$ & $68.9 \%$ \\
\hline The absence of sanctions & $15.2 \%$ & $21.6 \%$ & $63.2 \%$ \\
\hline
\end{tabular}

As seen in Table 6, the teachers also find that the factors favoring corruption are diverse. In fact, more than $60 \%$ of them agree on seven main factors. First, lack of values and principles is perceived as promoting corruption by $81.3 \%$ of teachers surveyed. The lack of a control system is perceived by $75.3 \%$ of respondents as a vector of corruption, followed by the absence of a culture of denunciation and the absence of sanctions (72.3\%). The flaws in the university system $(68.1 \%)$ and the trivialization of the phenomenon of corruption $(65.8 \%)$ are also mentioned.

Table 6. Factors perceived by teachers as favoring corruption in HE

\begin{tabular}{|l|c|c|c|}
\hline \multicolumn{1}{|c|}{ Factors of corruption } & Disagree & $\begin{array}{c}\text { Moderately } \\
\text { agree }\end{array}$ & Agree \\
\hline Low remuneration of teachers & $42.2 \%$ & $26.1 \%$ & $31.7 \%$ \\
\hline The low remuneration of administrative agents & $24 \%$ & $31.8 \%$ & $44.2 \%$ \\
\hline Lack of a culture of denunciation & $10 \%$ & $17.3 \%$ & $72.7 \%$ \\
\hline The flaws in the university system & $9.9 \%$ & $21.9 \%$ & $68.1 \%$ \\
\hline The trivialization of the phenomenon of corruption & $13.4 \%$ & $20.8 \%$ & $65.8 \%$ \\
\hline $\begin{array}{l}\text { Lack of values and principles among the different } \\
\text { actors }\end{array}$ & $5.1 \%$ & $13.6 \%$ & $81.3 \%$ \\
\hline $\begin{array}{l}\text { The incompetence of certain officials and / or } \\
\text { teachers }\end{array}$ & $14.7 \%$ & $26.1 \%$ & $59.2 \%$ \\
\hline The absence of a control system & $7.6 \%$ & $17.1 \%$ & $75.3 \%$ \\
\hline $\begin{array}{l}\text { The exaggerated familiarity between the different } \\
\text { actors (teachers-students, administration-students) }\end{array}$ & $21.3 \%$ & $31.7 \%$ & $47.1 \%$ \\
\hline Lack of sanctions & $14.3 \%$ & $13.4 \%$ & $72.3 \%$ \\
\hline
\end{tabular}

The administrators' judgments concerning the factors favoring corruption are more or less 
similar to those of teachers and students. Indeed, $68.3 \%$ think that the lack of values and principles significantly favors the phenomenon of corruption; $67.2 \%$ blame the university system's dysfunctions and flaws; $65.1 \%$ consider the absence of a control system to be the leading cause of corruption in academia. However, $61 \%$ perceive the incompetence of certain managers and/or teachers and the low remuneration of administrative staff as factors contributing to corruption; these two factors were not considered as significant by the other two categories of respondents.

Convergently, the three categories of educational actors believe that the absence of values, the lack of a culture of denunciation, and the lack of control/sanctions, are among the main factors favoring corruption in Moldovan Higher Education.

Cumulated structural dimension. The structural dimension of corruption in Moldovan Higher Education also emerges in a preponderant and consensual manner from the three categories of respondents' responses being explained by two main factors: (i) the university system's flaws and (ii) the absence of a control system. It seems, at first, that the Moldovan university system has accumulated over the years a set of flaws that have favored certain forms of corruption. This state of affairs has been reinforced by the absence of permanent and systematic control, capable, on the one hand, of detecting these flaws and, on the other hand, of spotting corrupt practices, mainly intangible and invisible. Control can also act as a warning signal and dissuade each actor from resorting to it. Besides, respondents' perceptions confirming the existence of corruption before and after 2014 suggest that this phenomenon is not the result of a particular conjuncture linked to a given context but rather testifies a structural problem.

\subsection{Dominant Aspects of Corruption in Moldovan Higher Education}

It is interesting to underline the convergence of the responses of the three categories of respondents regarding their perceptions of the forms that the phenomenon of corruption takes in academia (Table 7).

Table 7. Dominant forms of corruption as perceived by Students (S), teachers (T), and administrative staff (A)

\begin{tabular}{|l|c|c|c|c|c|c|c|c|c|}
\hline \multirow{2}{*}{$\begin{array}{c}\text { Forms of } \\
\text { corruption }\end{array}$} & \multicolumn{4}{|c|}{ Disagree } & \multicolumn{3}{c|}{ Moderately agree } & \multicolumn{3}{c|}{ Agree } \\
\cline { 2 - 10 } & S & T & A & S & T & A & S & T & A \\
\hline Abuse of power & $14 \%$ & $16.1 \%$ & $21.9 \%$ & $29 \%$ & $26.4 \%$ & $28.1 \%$ & $57 \%$ & $57.5 \%$ & $50 \%$ \\
\hline $\begin{array}{l}\text { Exchange of } \\
\text { services }\end{array}$ & $12.9 \%$ & $16 \%$ & $19.8 \%$ & $29.7 \%$ & $22.2 \%$ & $34.1 \%$ & $57.4 \%$ & $61.9 \%$ & $46.1 \%$ \\
\hline Bribes & $10.6 \%$ & $31,9 \%$ & $29,5 \%$ & $12.9 \%$ & $34.6 \%$ & $41 \%$ & $76.5 \%$ & $33.5 \%$ & $29.5 \%$ \\
\hline Favoritism & $13.6 \%$ & $10.9 \%$ & $9.5 \%$ & $16.4 \%$ & $28.5 \%$ & $33.3 \%$ & $70 \%$ & $60.6 \%$ & $57.1 \%$ \\
\hline $\begin{array}{l}\text { Willful } \\
\text { mismanagement }\end{array}$ & $21.6 \%$ & $24,5 \%$ & $12.5 \%$ & $35.7 \%$ & $21.8 \%$ & $45.3 \%$ & $42.7 \%$ & $53.7 \%$ & $42.2 \%$ \\
\hline Lack of ethics & $14.9 \%$ & $14.6 \%$ & $19,4 \%$ & $27.9 \%$ & $23.4 \%$ & $33.9 \%$ & $57.2 \%$ & $62 \%$ & $46.8 \%$ \\
\hline Voluntary & $12.7 \%$ & $18.5 \%$ & $22.6 \%$ & $19.8 \%$ & $22,7 \%$ & $25.8 \%$ & $67.5 \%$ & $58.8 \%$ & $51.6 \%$ \\
\hline
\end{tabular}




\begin{tabular}{|l|l|l|l|l|l|l|l|l|l|}
\hline $\begin{array}{l}\text { non-compliance } \\
\text { with laws }\end{array}$ & & & & & & & & \\
\hline $\begin{array}{l}\text { Unearned access } \\
\text { to positions of } \\
\text { responsibility }\end{array}$ & $11.3 \%$ & $13.5 \%$ & $14.1 \%$ & $19.2 \%$ & $17.1 \%$ & $28.1 \%$ & $69.5 \%$ & $69.4 \%$ & $57.8 \%$ \\
\hline
\end{tabular}

Four forms of corruption in HE emerged in a salient manner from respondents' declarations and can be categorized into four sections: (i) the administrative aspect, (ii) the exchange aspect, (iii) the relational aspect, and (iv) the legal aspect.

The first component affirmatively and overwhelmingly gathering the largest number of respondents from the three categories surveyed refers to undeserved access to positions of responsibility within the University (students 69.5\%, teachers 69.4\%, administrative personnel 57.8\%). The second component, an object of consensus between the three actors, is the exchange of services between the corrupter and the corrupt. The third component also recorded high agreement rates from all three categories of respondents and concerns cronyism, favoritism, and complacency. Finally, the last-mentioned aspect dominantly relates to voluntary non-compliance with the laws.

These results are eloquent since they show the complexity and subtlety of corruption in Higher Education, given the difficulty of detecting these four dominant forms' character. These conclusions are also corroborated by the mixed responses of teachers and administrators regarding bribes at the University. This result suggests that financial corruption is not a rare form in this sector and that students seem to be more aware of the commonness of this corruption practice at the university level. These findings can probably be explained by cultural factors linked to Moldovan society, a place where relationships weigh considerably in social and professional advancement, where exchanges of services are commonplace, and where corruption is gradually becoming a norm at all societal levels.

\subsection{The Responsibility for Corruption in Higher Education}

Given the main education actors' simultaneous involvement in the survey, the responsibility for corruption was supposed to be divided among them. Paradoxically, the results converge in a clear and focused manner towards a major role played by the administrative officials at two levels: that of the hierarchical top and that relating to the organizational base.

Table 8. Degree of responsibility for corruption in HE as perceived by students (S), teachers (T), and administrative staff (A)

\begin{tabular}{|l|c|c|c|c|c|c|c|c|c|}
\hline \multirow{2}{*}{$\begin{array}{c}\text { Forms of } \\
\text { corruption }\end{array}$} & \multicolumn{3}{|c|}{ Not or little responsible } & \multicolumn{2}{c|}{ Moderately responsible } & \multicolumn{4}{c|}{ Responsible } \\
\cline { 2 - 11 } & S & T & A & S & T & A & S & T & A \\
\hline Teachers & $23.6 \%$ & $38 \%$ & $38.5 \%$ & $35.5 \%$ & $32.3 \%$ & $27.7 \%$ & $40.9 \%$ & $29.7 \%$ & $33.8 \%$ \\
\hline Students & $35.2 \%$ & $44 \%$ & $43.8 \%$ & $26.7 \%$ & $29 \%$ & $23.4 \%$ & $38.2 \%$ & $26.9 \%$ & $32.8 \%$ \\
\hline $\begin{array}{l}\text { Adm-ve staff } \\
\text { and officials of } \\
\text { the HEI }\end{array}$ & $17.2 \%$ & $18.8 \%$ & $26.2 \%$ & $18.2 \%$ & $23 \%$ & $40 \%$ & $64.6 \%$ & $58.1 \%$ & $33.8 \%$ \\
\hline
\end{tabular}




\begin{tabular}{|l|l|l|l|l|l|l|l|l|l|}
\hline $\begin{array}{l}\text { Ministry of } \\
\text { Education }\end{array}$ & $30.9 \%$ & $36.1 \%$ & $41.5 \%$ & $23.9 \%$ & $27.3 \%$ & $24.9 \%$ & $45.2 \%$ & $36.6 \%$ & $33.5 \%$ \\
\hline $\begin{array}{l}\text { Unions } \\
\text { (teachers and/or } \\
\text { students) }\end{array}$ & $27.3 \%$ & $43.5 \%$ & $47.7 \%$ & $31.8 \%$ & $21.2 \%$ & $24.6 \%$ & $40.9 \%$ & $35.2 \%$ & $27.7 \%$ \\
\hline
\end{tabular}

First, students (64.6\%), teachers $(58.1 \%)$, and to a lesser extent, administrators themselves (33.8\%) believe that the administrative officials of HEI are primarily responsible for corruption at the Moldovan University. In addition, a good part of the administrative staff we questioned blame the high level of corruption on the Ministry of Education. It is essential to qualify this result. Indeed, the focus on the top of the administrative hierarchy within the Moldovan University or the supervisory authority does not mean a fortiori that the cited persons are corruptors or corrupted but could indicate two elements: (i) the respondents would consider that any laxity at the top of the hierarchy contributes to the spread of corruption or (ii) they would assume that the key positions at the top of the University or the supervisory authority impute de facto responsibility for any dysfunction related to this entity to its holder, including corruption. Then, the administrators, whether they are high officials or executives, are held responsible, especially by the teachers and the students, and to a lesser extent by the administrators themselves.

Therefore, in the respondents' opinion, corruption is a global system involving administrative officials at all levels, which goes beyond the narrow framework of the simple one-off act that revolves around the corrupter and the corrupt.

\subsection{Detection, Disclosure, and Elimination of Corruption}

For most of the students and teachers we questioned, all the proposed means of combating corruption in academia were considered effective (Table 9). More specifically, four actions appear effective for more than $70 \%$ of the respondents. Coercive action, applying existing sanctions to corrupt actors, is seen as the most effective one. Then comes the control action by strengthening the related procedures. The same level of perceived effectiveness was also recorded for the recruiting activity of appointing and recruiting honest, competent people. $87.8 \%$ of teachers also believe that the university system's transparency constitutes a strong anti-corruption action.

Table 9. Students and teachers' assessment of the effectiveness of anti-corruption actions

\begin{tabular}{|l|c|c|c|c|c|c|}
\hline \multirow{2}{*}{} & \multicolumn{2}{|c|}{ Ineffective } & \multicolumn{2}{c|}{ Moderately effective } & \multicolumn{2}{c|}{ Effective } \\
\cline { 2 - 7 } & $\mathbf{S}$ & $\mathbf{T}$ & $\mathbf{S}$ & $\mathbf{T}$ & $\mathbf{S}$ & $\mathbf{T}$ \\
\hline $\begin{array}{l}\text { Creation of a teachers discipline } \\
\text { council }\end{array}$ & $26 \%$ & $27.2 \%$ & $25.3 \%$ & $26.7 \%$ & $48.8 \%$ & $46.1 \%$ \\
\hline $\begin{array}{l}\text { Creation of a student council to } \\
\text { denounce cases of corruption }\end{array}$ & $15.6 \%$ & $26.2 \%$ & $24.7 \%$ & $25.7 \%$ & $59.8 \%$ & $48.2 \%$ \\
\hline Awareness actions for all stakeholders & $17.7 \%$ & $15.8 \%$ & $29.1 \%$ & $22.6 \%$ & $53.2 \%$ & $61.6 \%$ \\
\hline A political will to fight against the & $14.1 \%$ & $9.5 \%$ & $20.2 \%$ & $13.7 \%$ & $65.7 \%$ & $76.8 \%$ \\
\hline
\end{tabular}




\begin{tabular}{|l|c|c|c|c|c|c|}
\hline phenomenon & & & & & & \\
\hline $\begin{array}{l}\text { Appointment and recruitment of honest } \\
\text { and competent people }\end{array}$ & $9.7 \%$ & $6.3 \%$ & $17.2 \%$ & $5.3 \%$ & $73.1 \%$ & $88.4 \%$ \\
\hline $\begin{array}{l}\text { Transparency of the university system } \\
\text { (information system) }\end{array}$ & $10.3 \%$ & $3.7 \%$ & $19.2 \%$ & $8.5 \%$ & $70.5 \%$ & $87.8 \%$ \\
\hline $\begin{array}{l}\text { Communication of the rights and duties } \\
\text { of each actor }\end{array}$ & $13.9 \%$ & $8.9 \%$ & $25.3 \%$ & $15.8 \%$ & $60.8 \%$ & $75.3 \%$ \\
\hline Strengthening of control procedures & $9.5 \%$ & $9 \%$ & $17.1 \%$ & $11.6 \%$ & $73.5 \%$ & $79.4 \%$ \\
\hline $\begin{array}{l}\text { Strengthening the weight of unions } \\
\text { (students and / or teachers) }\end{array}$ & $15.2 \%$ & $27.3 \%$ & $24.4 \%$ & $25.7 \%$ & $60.4 \%$ & $47 \%$ \\
\hline $\begin{array}{l}\text { Establishment of a system for } \\
\text { evaluating teachers by students }\end{array}$ & $15.3 \%$ & $33.7 \%$ & $20.9 \%$ & $22.1 \%$ & $63.9 \%$ & $44.2 \%$ \\
\hline $\begin{array}{l}\text { Applying existing sanctions to corrupt } \\
\text { actors }\end{array}$ & $10.1 \%$ & $6.8 \%$ & $15.2 \%$ & $8.9 \%$ & $74.6 \%$ & $84.2 \%$ \\
\hline
\end{tabular}

The administrative personnel was particularly sensitive to the proposals for anti-corruption actions in HE since most of the respondents considered all these actions effective. Two means stand out notably. Thus, an overwhelming majority $(90.3 \%)$ of them agree that coercion action is the most relevant. Recruiting honest and competent people is also seen as effective for $88.7 \%$ of them. At this level, the opinions of administrators join the views of teachers and students. As compared to the other two categories of respondents, $75 \%$ of the administrative personnel is convinced of the effectiveness of good governance actions, and $70.6 \%$ believe in the relevance of communication actions. To a lesser extent, the control, training, and transparency procedures are deemed effective by more than $68 \%$ of the respondents.

Three types of actions emerge in a salient manner and are the subject of consensus among our respondents: coercion, control, and recruitment.

More coercion and less laxity. Applying existing sanctions to corrupt actors seems to be a strong demand among all the respondents. In general, this result tells us about two elements: (i) the awareness of these actors of a coercive mechanism concerning acts of corruption and (ii) the existence of certain impunity relating to acts of corruption in Moldovan higher education.

Therefore, it seems that the legal and regulatory framework governing the sanctioning of acts of corruption is not intrinsically called into question, but rather its application and implementation. This observation could probably represent one of the explanatory factors of the generalized crisis of confidence mentioned above and characterizing the relations between the three actors. It is also likely that the laxity perceived by the respondents constitutes a significant barrier to denunciation, especially since this action is considered risky. A real application and activation of the existing coercion system could signal the rigor and intransigence of the public authorities likely to motivate individuals to disclose corruption cases they witnessed or personally experienced.

Honesty and competence: main recruitment criteria The hiring system in the public service 
and, in particular, in the university system does not seem to meet the requirements of competence and honesty mentioned by respondents. This finding corroborates the results concerning the perceived causes of corruption attributable to certain actors' incompetence in the university system. It seems, moreover, that this characteristic is coupled with preponderant dishonesty. Again, this conclusion confirms the relevance of the factor relating to cultural and individual values favoring corruption. It is suggested that the recruitment mechanism be reviewed to guarantee, as a first step, the degree of competence required for a given function, thus rehabilitating the principle of "meritocracy," an essential engine of the social lift.

Strengthening control. One of the main causes of corruption identified by the respondents is the lack of control within the university system. Consistent with this result, they propose strengthening control and auditing, given the many existing flaws and deficiencies. Continuous review and verification can deter potential actors tempted by corrupt practices. They also make it possible to bypass the imposing omerta ${ }^{l}$ surrounding the phenomenon of corruption. Given the blockages that exist upstream of the act of denunciation, intense monitoring and follow-up can ease the heavy burden on the actors.

\section{Conclusions}

Beyond the main trends identified in the light of the study results, a more holistic reading is required to decipher the elements that make sense for our three categories of respondents and which are underlying their answers strictly relative to corruption at the Moldovan University. Three dominant ideas emerge and are detailed in what follows.

\subsection{Moldovan University: Social Elevator Broken}

The participants' different responses about the forms and manifestations of corruption made it possible to identify the Moldovan university system's current flaws. They also provide information on the multiplicity of these dysfunctionalities at several levels of the system. This observation calls into question the solidity and relevance of the Moldovan University's role as a social elevator, having to guarantee the same rights and chances of success and development to all the actors involved. Students or teachers entering higher education are driven by a legitimate personal ambition, which, unfortunately, and due to corrupt practices, can be broken and sometimes leads to deviant behavior. Therefore, corruption destabilizes universities' functioning and impacts the job market by disrupting training, selection, and progression mechanisms.

The dysfunctions resulting from corrupt practices at the University also undermine its image perceived by Moldovan society as an essential social lift. The propagation of such a tarnished image in society's different sections is likely to favor unethical practices and mediocrity. It would discredit the University in the eyes of families who would tend to doubt the University's potential for social advancement.

(1)A rule or code that prohibits speaking or divulging information about certain activities, especially the activities of a criminal organization. (2) The code of silence in the Mafia, from the Italian word for "humility. (https://www.thefreedictionary.com/Omert\%C3\%A0) 


\subsection{A generalized crisis of confidence}

As perceived by the three actors of the Moldovan University, corrupt practices reflect a specific confidence crisis among them. Each category tends to relieve itself of the guilt concerning the phenomenon of corruption but is often singled out by the other two categories. The current structure of the Moldovan university system can only fuel this tripartite mistrust. Indeed, the three entities are often completely disconnected, registering a notable deficit in communication and interactions.

Outside the narrow framework of educational exchange between students and teachers, these two actors operate in isolation within the University, and communication bridges are generally broken. In this configuration, it is difficult to treat the problem of corruption thoughtfully and investigate it objectively. Rather, it appears to be a framework of possible confrontation.

Moreover, administrative heaviness and rigidity often dissuade students and teachers from crossing the barrier, separating them from the administration, which already suffers from a bad reputation in Moldovan citizens' minds. The crisis of confidence is more pronounced at this level through many cases of injustice recorded previously. Not having been the subject of a real objective investigation, these cases only discredited the administration in Moldovan university key actors' eyes.

\subsection{Shaken Values and Principles}

Among the factors favoring corruption at University, one component has emerged prominently and concerns the absence of individual values and principles. The ethical and moral aspect is, therefore, closely linked to the phenomenon of corruption. In this respect, it is important to stress that, contrary to received or propagated ideas, the financial difficulties related to teachers' and administrators' possible low salaries do not constitute factors justifying corruption. The participants thus believe that corruption in general and educational corruption, in particular, is an essentially ethical and non-financial problem and results from the deficit of values and principles such as honesty, righteousness, fairness, etc. among the Moldovan citizens in general and educational actors in particular.

\subsection{An Omnipresent Law of Silence}

Like the global phenomenon of corruption, Moldovan academia suffers from an omerta (code of silence) around this issue. Two factors can explain this finding. On the one hand, the lack of a visible structure for reporting or monitoring corruption reinforces the silence and dissuades those concerned from speaking out publicly. On the other hand, a certain "community" solidarity obliges members to refuse to submit denunciations or testimonies in order to avoid any exclusion from the "clan" or any possible marginalization that could significantly harm their development. In addition, the nature of the Moldovan University's functioning makes denunciation difficult and, above all, risky. The fear of possible reprisals could, therefore, discourage the individuals. 
Corruption in higher education institutions is not an isolated case but an integral part of the net of corrupt relations that dominate the country. Its consequences for education and society are destructive because it affects social mobility and the country's human capital formation. The causes of corruption find their roots in the ineffective human and procedural management within the Higher Education, Moldovan culture, and various educational actors' behavior.

According to those interviewed, fighting corruption in the education sector requires more effective and transparent management and increased stakeholders' awareness and involvement. Based on our study and our respondents' suggestions, some interesting points of reflection that could play the role of strategic anti-corruption actions were identified. A combined fight against the roots and different facets of corruption in higher education requires the active and committed involvement of the academic world, civil society, and public authorities for:

- Better governance and management of the university system;

- Increased awareness about the extent and consequences of corruption in the university environment;

- The establishment of an anonymous and secured system that would facilitate the denouncement of corruption in all its forms;

- The active promotion of values and the teaching of ethics in schools starting from an early age;

- The implementation of control methods in universities such as internal and external audit;

- The establishment of a system of effective sanctions and strict monitoring regarding their rigorous and inevitable application;

- The creation of students' and teachers' associations to facilitate the denouncement of corruption and alert the judicial authorities about corruption-related cases.

\section{Contributions and Prospects for Improvement}

This study, of an exploratory nature, constitutes a first step in investigating the phenomenon of corruption in Moldovan Higher Education, a subject that still suffers from the weight of the unspoken and remains delicate to study. However, this paper does not claim to lead to an accurate, detailed diagnosis of the corruption phenomenon. Therefore, the results should be considered exclusively through a perceptual prism. This prism is nevertheless essential because it often guides and directs the actions or even inactions of the Moldovan university system's various actors. We believe it necessary to complete this study with diagnostic research going beyond the actors' perceptions and scanning in a detailed and expert way the Moldovan university system's components so that the loopholes favoring the phenomenon of corruption could be detected and eliminated.

Two significant contributions should be noted at the methodological level. First, 
measurement scales relating to corruption at the University, admittedly requiring confirmatory studies, were created following a two-step academic approach by crossing a qualitative approach with a quantitative methodology. Thus, a first qualitative study was carried out to explore this particular theme and identify the main items making up the measurement scales. A second quantitative study made it possible to probe the three key players in academia and test the measurement scales created.

From a strategic standpoint, this study is likely to help the overall anti-corruption efforts initiated in the Republic of Moldova after 2014. This paper can already constitute a first rich and consistent material allowing international partners and public authorities to understand better the existent corruption perceptions in academia and the future projects, strategies, and actions to be undertaken around this extremely sensitive subject. Identifying the key trends characterizing the visions of the three categories of respondents and considering their suggestions and proposals can effectively guide the strategic orientations in the fight against corruption in Moldovan Higher Education.

\section{References}

Altbach, P. (2004). The question of corruption in academe. International Higher Education, 34, 7-8. https://doi.org/10.6017/ihe.2004.34.7399

Bardhan, P. (1997). Corruption and Development: A Review of Issues. Journal of Economic Literature, 35(3), 1320-1346. Retrieved January 4, 2021, from http://www.jstor.org/stable/2729979

Blackburn, K., Bose, N., \& Haque, M. E. (2002). Endogenous Corruption in Economic Development. Centre for Growth and Business Cycle Research Discussion Paper Series, 22. Economics, The University of Manchester.

Cabelkova, I., \& Hanousek, J. (2004). The power of negative thinking: corruption, perception, and willingness to bribe in Ukraine. Applied Economics, Taylor \& Francis Journals, vol. 36(4), pp. 383-397. https://doi.org/10.1080/00036840410001674303

Campbell, N., \& Saha, S. (2013). Corruption, democracy, and Asia-Pacific countries. Journal of the Asia Pacific Economy, 18(2), 290-303. https://doi.org/10.1080/13547860.2013.778156

Chapman, D. (2002). Sectoral perspective on corruption: Corruption and the education sector. MSI. Available online at http://millenniumchallengecorporation.net/ our_work/democracy _and_governance/publications/ac/sector/education.doc

Creswell, J. (2009). Research design: Qualitative, quantitative, and mixed methods approach. Los Angeles: Sage.

Creswell, J. W. (2012). Educational research: Planning, conducting, and evaluating quantitative and qualitative research (4th ed.). Boston, MA: Pearson.

Everhart, S., Vazquez, J. M., \& McNab, R. M. (2009). Corruption, governance, investment, and growth in emerging markets. Applied Economics, 41(13). https://doi.org/10.1080/00036840701439363 
Frimpong, K., \& Jacques, G. (1999). Corruption, Democracy and Good Governance in Africa: Essays on Accountability and Ethical Behavior. LightbooksLtd, Botswana.

Hallak, J., \& Poisson, M. (2009). Ecoles Corrompues, Universités Corrompues: Que Faire? Ed Unesco, 358 p. https://doi.org/10.1086/524367

Heyneman, S. P. (2002), Education and Corruption, Annual Meeting of the Association for the Study of Higher Education (ASHE), November 20, Sacramento, CA. Available at: http://pdc.ceu.hu/archive/00004170/01/EducCorrupt.pdf.

Heyneman, S. P. (2004). Education and Corruption. International Journal of Educational Development, 24, 637- 648. https://doi.org/10.1016/j.ijedudev.2004.02.005

Heyneman, S. P., Anderson, K., \& Nuralieva, N. (2007) The cost of Corruption in Higher Education. Comparative Education Review, 52(1), 2-25. Available online at https://etico.iiep.unesco.org/sites/default/files/Heyneman.2008.CostsofCorruption.pdf

International Republican Institute (IRI), (2019). Public Opinion Survey: Residents of Moldova. Available online at https://www.iri.org/sites/default/files/iri_poll_-_december _2019_for_publishing.pdf.

Institute for Public Policy (IPP), (2018). Ethics and academic integrity in schools. Informal payments. A sociologic study, MD - Chisinau 2018. Available online at https://ipp.md/wp-content/uploads/2018/10/7.-Etica-si-integritatea-academica.pdf

Johnston, M. (1996). The search for definitions: The vitality of politics and the issue of corruption. International social science journal, 48, 321-335. https://doi.org/10.1111/1468-2451.00035

Kalnins, V. (2001). Latvia's Anti-corruption Policy: Problems and Prospects. Riga: Soros Foundation. https://liia.lv/site/attachments/17/01/2012/Kaln_kor_liel_EN.pdf

Kaufmann, D., Montoriol-Garriga, J., \& Recanatini, F. (2008). How does bribery affect public service delivery? Micro evidence from service users and public officials in Peru. World Bank Institute: Global Programs Group. https://doi.org/10.1596/1813-9450-4492

León, C., Araña, J., \& De León, J. (2013). Correcting for Scale Perception Bias in Measuring Corruption: An Application to Chile and Spain. Social Indicators Research, 114(3), 977-995. https://doi.org/10.1007/s11205-012-0185-7

Melgar, N., Rossi, M., \& Smith. (2010). The perception of corruption. International Journal of Public Opinion Research, 22, 120 - 131. https://doi.org/10.1093/ijpor/edp058

Milovanovitch, M. (2014). Fighting Corruption in Education: A Call for Sector Integrity Standards. World Bank Legal Rev., 5, 367. https://doi.org/10.1596/978-1-4648-0037-5_ch19

Mishler, W. (2008). Seeing Is Not Always Believing: Measuring Corruption Perceptions and Experiences. Available online at: https://www.researchgate.net/publication /242111254_Seeing_Is_Not_Always_Believing_Measuring_Corruption_Perceptions_and_Ex periences. 
Mitchell, R. C., \& Carson, R. T. (1989). Using Surveys to Value Public Goods: The Contingent Valuation Method. Resources for the Future, Washington DC.

Montesquieu, Charles de Secondat, (2002). The Spirit of Laws. Amherst, NY: Prometheus Books.

National Bureau of Statistics of the Republic of Moldova. (2019). Education in the Republic of Moldova. https://statistica.gov.md/newsview.php?l=ro\&idc=168\&id=6547

Neuman, W. L. (2014). Social Research Methods: Qualitative and Quantitative Approaches (7th ed.). Essex: Pearson. Available at: http://letrunghieutvu.yolasite.com/resources/w-lawrence-neuman-social-research-methods_-q ualitative-and-quantitative-approaches-pearson-education-limited-2013.pdf

Olken, B. A., \& Pande, R. (2012). Corruption in Developing Countries. Annual Review of Economics, Annual Reviews, 479-509. https://doi.org/10.1146/annurev-economics-080511-110917

Osipian, A. L. (2009). Corruption and reform in higher education in Ukraine. Canadian and International Education/Education canadienne et internationale, 38(2), 104-122. https://doi.org/10.5206/cie-eci.v38i2.9139

Palmier, L. (1983). Bureaucratic Corruption and Its Remedies. in Clark, M. (ed.), Corruption: Causes, Consequences, and Control, Pinter, London.

Ross, L. (1977). The Intuitive Psychologist and His Shortcomings: Distortions in the Attribution Process. In L. Berkowitz (Ed.). Advances in Experimental Social Psychology. New York: Academic Press, 173-220. https://doi.org/10.1016/S0065-2601(08)60357-3

Rumyantseva, N. (2005). Taxonomy of Corruption in Higher Education. Peabody Journal of Education, 80(1), 81-92. https://doi.org/10.1207/S15327930pje8001_5

Shleifer, A., \& Vishny, R. W. (1993). Corruption. Quarterly Journal of Economics, 108(3), 599-617. https://doi.org/10.3386/w4372

Tanzi, V., \& Davoodi, H. (1997). Corruption, public investment, and growth. International Monetary Fund. Working Paper No. WP/97/139. https://doi.org/10.5089/9781451929515.001

United Nations Development Programme (UNDP). (2008). A users' guide to measuring corruption, UNDP Oslo Governance Centre.

Urra, F. J. (2007). Assessing corruption: An analytical review of corruption measurement and its problem: Perception, error, and utility. Available online at http://unpan1.un.org/intradoc/groups/public/documents/APCITY/UNPAN028792.pdf.

Waite, D., \& Allen, D. (2003). Corruption and abuse of power in educational administration. Urban Review, 35(4). https://doi.org/10.1023/B:URRE.0000017531.73129.4f 


\section{Copyright Disclaimer}

Copyright for this article is retained by the author(s), with first publication rights granted to the journal.

This is an open-access article distributed under the terms and conditions of the Creative Commons Attribution license (http://creativecommons.org/licenses/by/4.0/). 